\title{
Activity of Medial Mesopontine Units during Cataplexy and Sleep- Waking States in the Narcoleptic Dog
}

\author{
J. M. Siegel, ${ }^{1,2}$ R. Nienhuis, ${ }^{1,2}$ H. M. Fahringer, ${ }^{1,2}$ C. Chiu, ${ }^{1,2}$ W. C. Dement, ${ }^{3}$ E. Mignot, ${ }^{3}$ and R. Lufkin ${ }^{4}$ \\ 'Neurobiology Research 151A3, VAMC, Sepulveda, California 91343, ${ }^{2}$ Department of Psychiatry and Brain Research \\ Institute, UCLA School of Medicine, Los Angeles, California 90024, '3epartment of Psychiatry, Stanford University \\ School of Medicine, Palo Alto, California 94305, and ${ }^{4}$ Department of Radiology, UCLA School of Medicine, \\ Los Angeles, California 90024
}

Narcolepsy has been hypothesized to be a disease of rapid eye movement (REM) sleep. According to this hypothesis, cataplexy is a result of the triggering during waking of the mechanism that normally serves to suppress muscle tone in REM sleep. REM sleep control mechanisms have been localized to the pons. Narcoleptic dogs have increased numbers of cholinergic receptors in the medial pons. These findings suggest that neurons mediating the triggering of cataplexy might be located in medial pontine regions. In the present study, this hypothesis has been investigated by recording the discharge of units in the medial mesopontine region of the narcoleptic dog. Unit activity was examined in the nucleus reticularis pontis oralis, caudalis, and central gray, with each cell being recorded during both cataplexy and sleep states. Maximal discharge rates were observed, in all of these regions, during active waking states (mean rate, 45.3/sec) and REM sleep (16.0/sec), with minimal discharge rates in non-REM sleep (8.3/sec). Unit discharge was reduced in catoploxy relative to precataplexy peripds, cataplexy discharge rates were $8.3 / \mathrm{sec}, 52 \%$ of the mean REM sleep rate. Cataplexy discharge rates were also significantly lower than those at REM sleep onset. Cataplexy discharge rates were comparable to rates in quiet waking and nonREM sleep.

While medial mesopontine neurons discharge at high rates in REM sleep, they have little or no activity in cataplexy. We interpret the lack of activation of medial mesopontine units in cataplexy as indicating that the characteristic phasic motor activation of REM sleep does not occur in this state. We found that eye movements were significantly reduced in cataplexy relative to eye movements in waking periods preceding cataplectic attacks and relative to eye movements at REM sleep onset and during REM sleep.

We hypothesize that cataplexy is a result of the pathological waking activity of neurons that are normally selectively active in relation to the muscle tone suppression of REM sleep, combined with the sudden reduction of activity in brainstem neurons that are active in both REM sleep and waking. We have found REM-cataplexy-on cells in the medial

Received July 3, 1991; revised Nov. 11, 1991; accepted Nov. 26, 1991

This research was supported by the Medical Research Service of the Veterans Administration and by PHS Grants NS14610, HL41370, and NS23724.

Correspondence should be addressed to J. M. Siegel, Neurobiology Res. 151A3, VAMC, Sepulveda, CA 91343.

Copyright (C) 1992 Society for Neuroscience $0270-6474 / 92 / 121640-07 \$ 05.00 / 0$ medulla. If these medullary cells are being driven by pontine cells, cataplexy-on cells may be present in more lateral pontine regions. If cataplexy-on cells are also absent from these pontine regions, it would suggest that the activity of cataplexy-on cells is being triggered by medullary mechanigms.

Narcolepsy is a disease characterized by excessive daytime sleepiness, hypnagogic hallucinations, sleep onset REM periods, sleep paralysis, and cataplexy. Cataplexy is a loss of muscle tone in waking, usually precipitated by sudden, strong emotions. The symptoms of narcolepsy have been hypothesized to represent a pathological release of REM sleep processes into waking (Rechtschaffen et al., 1963). However, while cataplexy and sleep paralysis have a loss of muscle tone similar to that seen in REM sleep, these states are distinct from REM sleep in that consciousness is preserved (Guilleminault, 1976). It is unclear if other aspects of REM sleep physiology, such as altered autonomic activity, changes in thermoregulation, respiration, and phasic motor activation (Siegel, 1989) are present in cataplexy, or if atonia is the only common element.

The development of the narcoleptic dog model makes it possible to investigate these questions at the neuronal level. The narcoleptic dog presents dramatic episodes of cataplexy elicited by food presentation and play. Canine cataplexy is altered by pharmacological manipulations in a way that parallels the human condition (Baker and Dement, 1985; Mitler et al., 1987; Mignot et al., 1989). As in human narcolepsy, cataplexy develops postnatally in dogs and shows some improvement with age. Also as in the human condition, canine cataplexy is genetically determined (Honda et al., 1984; Baker and Dement, 1985; Mitler et al., 1987).

Studies of narcoleptic dogs and narcoleptic humans have found a marked upregulation of cholinergic ( $\mathrm{ACh}$ ) receptors in the medial mesopontine region (Boehme et al., 1984; Kilduff et al., 1986; Aldrich et al., 1990). Injection of cholinergic agonists in the medial mesopontine reticular formation regions of intact cats produces a loss of muscle tone without loss of consciousness that resembles cataplexy (Mitler and Dement, 1974) or a REM sleep-like state (George et al., 1964; Van Dongen, 1978; Katayama et al., 1984; Baghdoyan et al., 1987) depending on the exact injection site. Recent work in acute preparations has shown that microinjection of glutamate and corticotropin-releasing factor in the mesopontine region also induces atonia (Lai and Siegel, 1988, 1992). The receptor upregulation combined with the loss of muscle tone with chemical stimulation of this area suggests that it may be activated during both cataplexy and REM 
sleep. In the present study, we have recorded from cells in medial mesopontine and adjacent regions during sleep-waking states and cataplexy.

\section{Materials and Methods}

Three narcoleptic dogs, a female I abrador Retriever, a male Doberman Pinscher, and a female Doberman Pinscher, were bred at the Stanford University narcoleptic dog colony and transported to Los Angeles at the age of 8 months. Studies were performed over the next 3-10 month period. In an initial surgery, magnetic resonance (MR)-compatible highnickel stainless-steel needles (Lufkin et al., 1987; Duckwiler et al., 1990) were implanted over the mesopontine reticular formation and mounted to the skull with Teflon screws and acrylic. The scalp was closed and MR imaging in the sagittal, coronal, and horizontal planes was performed under thiopental anesthesia. All scans were performed on a Fonar B-3000 M (Melville, NY) MR machine with a 0.3 tesla hybrid magnet utilizing a $256 \times 256$ matrix with $4.7 \mathrm{~cm}$ slice thickness and 1.28 pixels $/ \mathrm{mm}$. Spin echo pulse sequences were used to produce T1 weighted images with a repetition time of $500 \mathrm{msec}$ and an echo time of $28 \mathrm{msec}$. The MR scans were then used to adjust stereotaxic coordinates using the implanted cannulas and the posterior limit of the inferior colliculus as reference points. The use of MR scanning was necessary because of the variability of skull size and resulting stereotaxic location of mesopontine targets. The correspondence between the stereotaxic atlas (Lim et al., 1960) and actual brain coordinates was found to be poor, with $1-5 \mathrm{~mm}$ deviations from the atlas in all three planes.

Using the adjusted stereotaxic coordinates, microdrives similar to those developed for the cat (Siegel et al., 1983) were implanted in a second surgery under thiopental, followed by halothane/oxygen anesthesia. After removal of the MR-compatible electrodes, bundles of seven Formvar-insulated microwircs, three of which were $62 \mu \mathrm{m}$ and four of which were $32 \mu \mathrm{m}$ (California Fine Wire, Grover City, CA), were inserted into each of two double-barreled microdrives. Screw electrodes were implanted in the frontal sinus caudal to the orbit for electrooculogram (EOG) recording, and over the central sulcus and posterolateral cortex for EEG recording. Four stranded stainless steel electrode wires were placed in the dorsal neck musculature for independent recording of tone of the left and right nuchal musculature.

After recovery from surgery, microwires were scanned in waking, REM sleep, and cataplexy, in freely moving narcoleptic dogs, to identify units. Units were then followed through the sleep-waking cycle. During all recording sessions, wircs on which cclls had previously been recorded were scanned, in cataplexy and all sleep-waking states. This maximized the possibility of identifying cells with state-specific activity. Unit activity was counted on line and displayed polygraphically at $10 \mathrm{sec}$ intervals. Cataplexy was elicited by the introduction of favored wet foods (Siegel et al., 1991). In some cases, physostigmine $(0.05 \mathrm{mg} / \mathrm{kg}$, i.v.) was administered to increase the frequency of cataplexy. Long cataplexies exceeding $90 \mathrm{sec}$ in duration and cataplexies leading directly into REM sleep were not observed under our recording conditions. Such phenomena are occasionally observed in severely affected narcoleptic dogs and humans.

Data were scored for sleep state using the usual criteria (Siegel et al., 1989). Cataplexy onset was defined as the start of a period of bilateral suppression of activity in the nuchal muscles leading to a suppression of tone lasting a minimum of 5 sec. Cataplexy offset was identificd by the return of activity to these muscles. Active waking rates were derived from the $10 \mathrm{sec}$ period preceding cataplexy onset. Unit discharge rates in quiet waking and non-REM sleep states were calculated as the mean rate for a representative $10 \mathrm{sec}$ interval. REM sleep rates were based on the entire REM sleep period. In our comparison of cataplexy, initial REM sleep, and mean REM sleep rates, the entire epochs were scored. The presence or absence of eye movements was scored for each consecutive $1 \mathrm{sec}$ interval of cataplexy and REM sleep.

\section{Results}

A total of 92 medial mesopontine units was recorded. Units whose signal-to-noise ratios fell below 3:1 at any point in the recording were dropped from the data sample. Forty-nine cells were recorded during all sleep states and during at least one cataplexy episode with signal-to-noise ratio maintained over 3:1. Units were localized to the nucleus reticularis pontis cau-

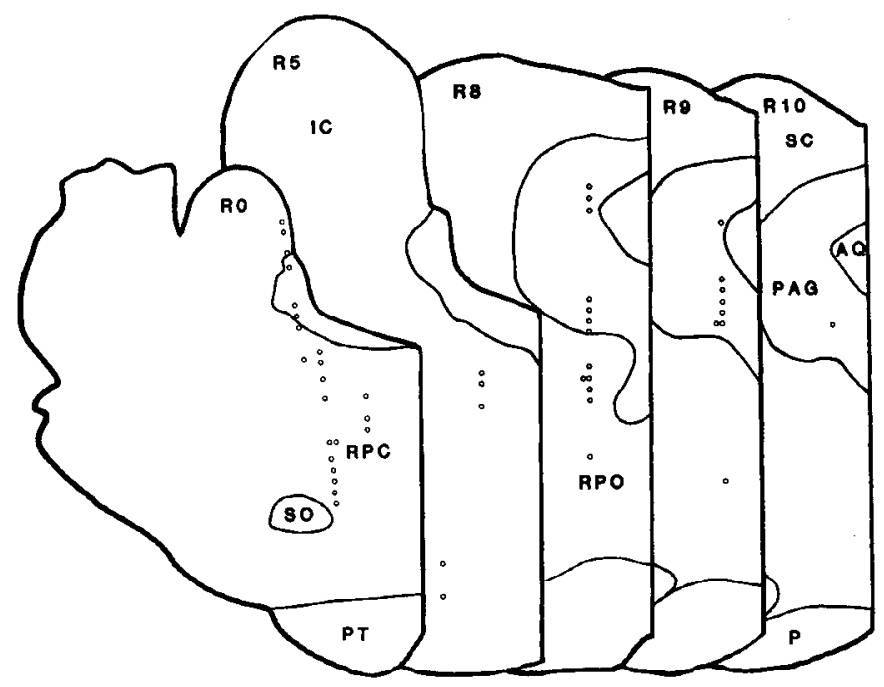

Figure 1. Plot of recorded cells at coronal levels R0 to R10 from the Lim et al. (1960) atlas. $R P C$, Nucleus reticularis pontis caudalis; $S O$, superior olive; $P T$, pyramidal tract; $I C$, inferior colliculus; $R P Q$, nucleus reticularis pontis oralis; $S C$, superior colliculus; $P A G$, periaqueductal gray; $A Q$, cerebral aqueduct; $P$, nucleus pontis.

dalis and oralis of the medial pons, corresponding to the FTG and FTL in the Berman (1968) nomenclature and to the central gray (Fig. 1). The discharge rates of medial mesopontine units located outside of the central gray did not differ significantly from those of central gray units (Table 1).

All units encountered had spontaneous activity in waking, with maximal discharge rates during movement, as we have previously seen in the analogous mesopontine regions of normal cats (Fig. 2) (Siegel and Tomaszewski, 1983; Siegel et al., 1983). Waking discharge was associated with directionally specific movements of the head and neck, as in the cat. Also, as in the cat, these units had high discharge rates in REM sleep and relatively low discharge rates in non-REM sleep (Figs. 3, 4). Cataplexies typically occurred during active waking periods and invariably were accompanied by an abrupt reduction in discharge rate. Figure 5 shows the activity of a pair of simultaneously recorded units during cataplexy. Unit activity and eye movements were reduced during cataplexy relative to pre- and postcataplexy periods. Cataplexy durations ranged from 12-74 sec (mean, $30.2 \pm 14.9 \mathrm{sec}$ ). All units were recorded during cataplexies following physostigmine administration and eight of the units were also recorded during cataplexies occurring without prior drug treatment. Unit discharge rates in cataplexies under the two conditions were not significantly different; the mean rate during cataplexies induced after physostigmine treatment was $8.3 / \mathrm{sec}$, while the rate during cataplexies induced without drug treatment was $11.1 / \mathrm{sec}(p>0.5$, paired $t$ test). For purposes of statistical comparison, the 49 cataplexies induced after physostigmine were used.

Discharge rate varied with arousal state $(p<0.001$, two-way ANOVA). During elicited and spontaneous cataplexy, mesopontine units significantly decreased discharge relative to the immediately preceding waking rate $(p<0.05$, Duncan's post hoc multiple range test). Cataplexy rates were significantly lower than REM sleep rates ( $p<0.05$, Duncan) and were comparable to non-REM and quiet waking rates. We saw no units selectively active in cataplexy or with increased activity in both cataplexy and REM sleep. 


\section{PONTINE CAT-OFF CELL}

\section{WAKING/CATAPLEXY}

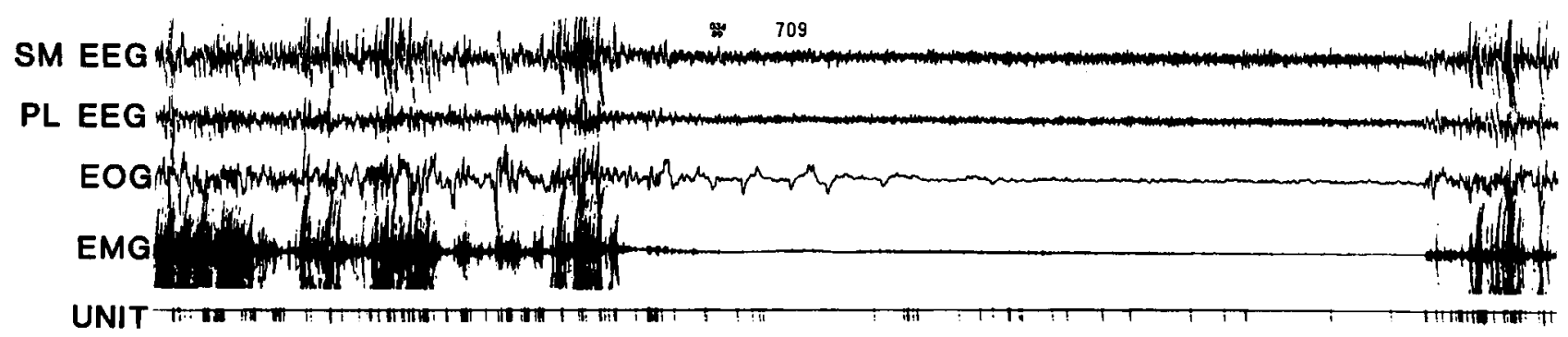

REM SLEEP

SM EEG

PL EEG

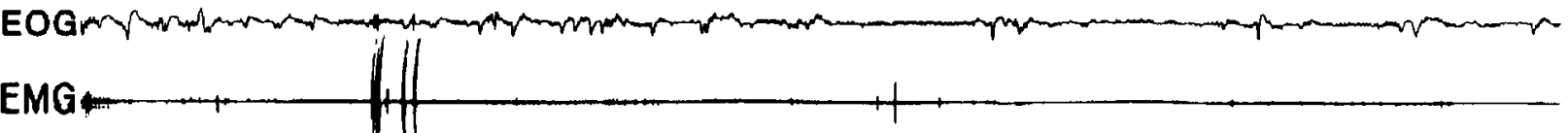

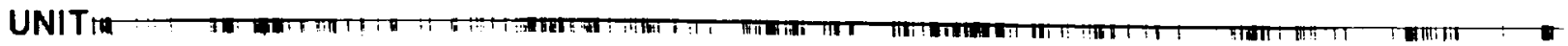

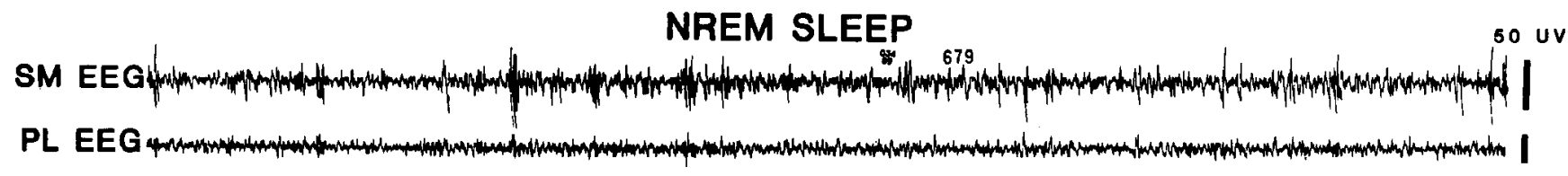

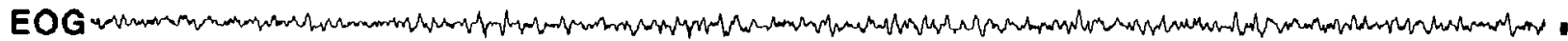
EMG

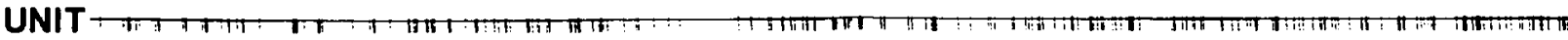

10 SECONDS

Figure 2. Polygraph record of pontine cell showing reduction in discharge rate with cataplexy. Discharge rate is maximal in active waking and REM sleep, and intermediate in non-REM sleep. SM EEG. Sensorimotor cortex electroencephalogram; $P L$, posterolateral cortex electroencephalogram; $E O G$, electrooculogram; $E M G$, nuchal electromyogram; UNIT, pulse output of window discriminator triggered by unit.

Cataplexy intervals are considerably shorter than REM sleep periods. Since mean REM sleep discharge rates of mesopontine units are greater than their rates at REM sleep onset, we tested for the possibility that cataplexy rates might be similar to REM sleep onset rates. We found that medial mesopontine unit discharge rates were significantly lower in cataplexy than those in the same duration interval at REM sleep onset $(p<0.01$, twotailed paired $t$ test; Fig. 6). Thus, medial mesopontine unit activity in cataplexy is not like REM sleep activity, when compared either to REM sleep onset or to the entire REM sleep period. We also found that the eye movement rate in cataplexy was significantly lower than that at REM sleep onset (Fig. $7 ; p$ $<0.01$, two-tailed paired $t$ test).

We examined patterns of interspike intervals to determine if there might be some similarity in cataplexy and REM sleep pattern. However, we found that discharge pattern, as assessed by interspike interval histograms and autocorrelograms showed no clear correspondence in cataplexy and REM sleep, even in those cells with discharge rates in cataplexy high enough to allow the calculation of meaningful spike train statistics. In general,

Table 1. Discharge rates of mesopontine cells in sleep-waking states and cataplexy \pm SE $(n=49)$

\begin{tabular}{|c|c|c|c|c|c|}
\hline & QW & AW & Cataplexy & REM & non-REM \\
\hline All cells $(n=49)$ & $8.8 \pm 1.8$ & $45.3 \pm 8.2$ & $8.3 \pm 1.5$ & $16.0 \pm 3.5$ & $8.3 \pm 1.4$ \\
\hline Central gray $(n=18)$ & $7.5 \pm 3.2$ & $39.5 \pm 12.6$ & $5.8 \pm 2.0$ & $9.8 \pm 3.1$ & $4.5 \pm 1.5$ \\
\hline RPO-RPC $(n=31)$ & $9.5 \pm 2.1$ & $48.6 \pm 10.8$ & $9.8 \pm 2.1$ & $19.6 \pm 5.2$ & $10.5 \pm 1.9$ \\
\hline
\end{tabular}

$\overline{\mathrm{QW}}$, quiet waking; $\mathrm{AW}$, active waking; $\mathrm{RPO}-\mathrm{RPC}$, nuclei reticularis pontis oralis-reticularis pontis caudalis. 


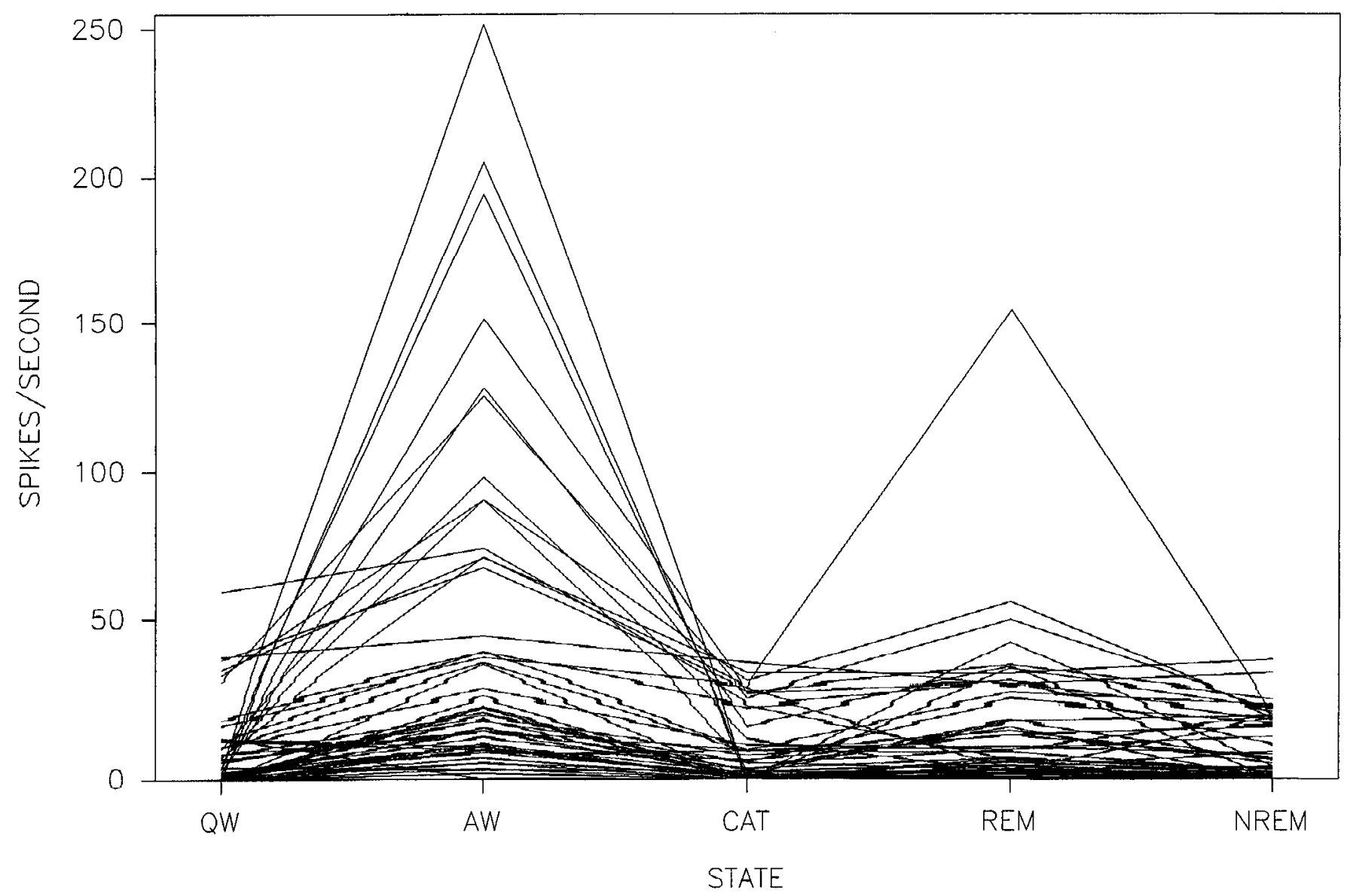

Figure 3. Rate diagram indicarifig discharge rate as a function of state of cells plotted in Figure 1. QW, Quiet waking; $A W$, active waking; $C A T$, cataplexy; REM, REM sleep; NREM, non-REM sleep.

interspike interval histograms and autocorrelogram spike distributions were a function of rate, so that cataplexy patterns most closely resembled those of non-REM and quiet waking states.

\section{Discussion}

We found that medial mesopontine neurons in the narcoleptic dog have significantly reduced activity in cataplexy relative to both mean REM sleep and active waking rates. Discharge rates fell sharply at cataplexy onset from those present in the precataplexy period. Cataplexy rates were also significantly lower than rates at REM sleep onset.

The majority of medial mesopontine neurons seen in this and previous studies discharge in relation to head, neck, thoracic, and related movements in waking (Rose, 1978; Siegel, 1979; Siegel and Tomaszewski, 1983; Siegel et al., 1983; Ni et al., 1990). We have interpreted their burst-pause discharge pattern in REM sleep as indicating that head, neck, and other axial movements are being commanded in this state, with their expression blocked by motoneuron hyperpolarization (Chase and Morales, 1989). This interpretation is supported by the release of such motor activities after lesions disrupting the system responsible for motor neuron hyperpolarization in REM sleep (Jouvet and Delorme, 1965; Henley and Morrison, 1974). It would follow from the above, and from our present findings, that central motor activation in cataplexy is reduced from precataplexy and RFM sleep levels.
Our eye movement data support this interpretation. Eye movements decrease from prior waking levels at cataplexy onset. Eye movement levels in cataplexy are significantly lower than those in REM sleep and at REM sleep onset. These results, however, are somewhat surprising since one might expect attempted movements from the conscious paralyzed animals. Perhaps the expression of any such "willed" movements is blocked before it reaches mesopontine levels. Such a blockade or disfacilitation might have a role in the triggering of cataplexy. However, our previous work showing incrcascd activity in a subpopulation of REM sleep active neurons in the medial medulla during cataplexy (Siegel et al., 1991) suggests that an active inhibitory mechanism is at least partially responsible for cataplexy.

Recent work in our laboratory in the decerebrate preparation has demonstrated that both atonia and motor activation are generated by colucalized pontomedullary systems, including the pedunculopontine/laterodorsal tegmental nuclei (PPN/LDT) and reticularis pontis oralis (RPO) regions, thus providing a mechanism for the generation of the "paradoxical" combination of muscle atonia with motor activity that characterizes REM sleep (Lai and Siegel, 1990). Further work has shown that non-NMDA glutamate receptors mediate the muscle tone suppression, while NMDA receptors mediate the motor activation elicited from atonia sites (Lai and Siegel, 1991). The presence of atonia without motor activation in cataplexy suggests a functional dissociation of the NMDA-mediated motor activation system from the non-NMDA-mediated atonia system. 


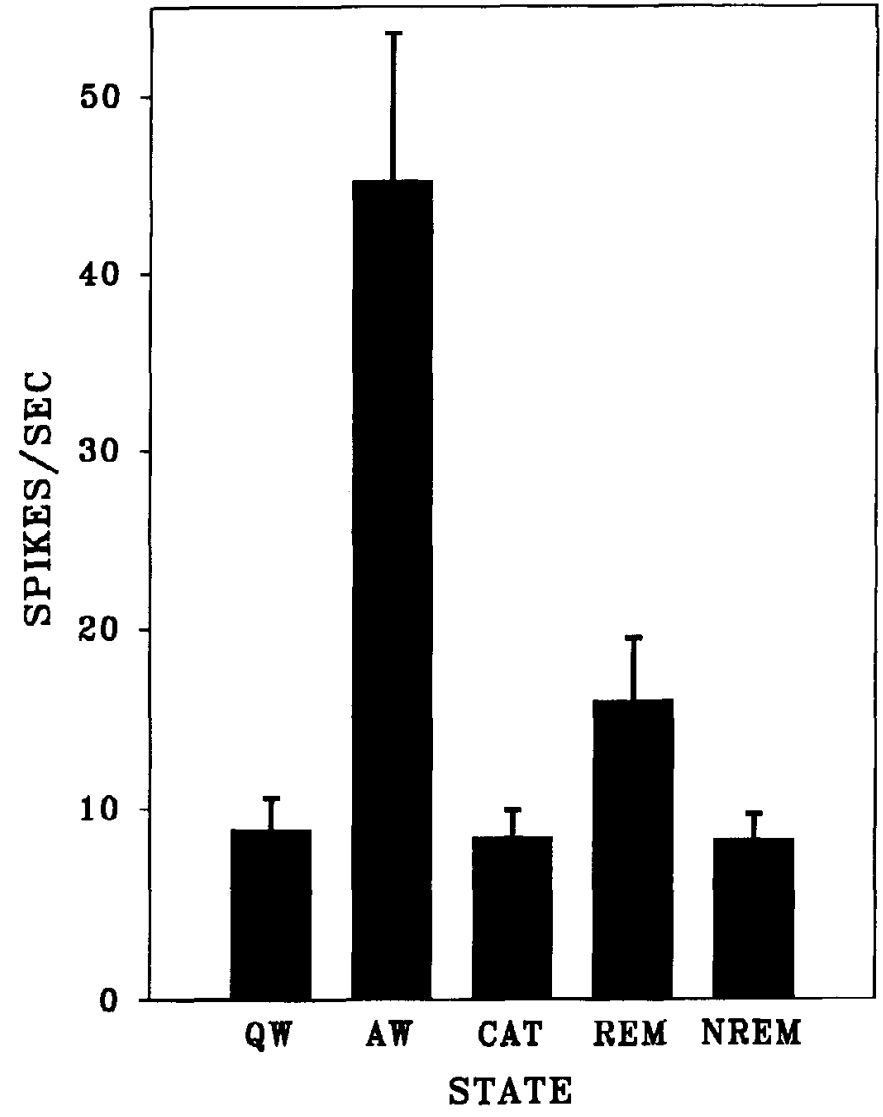

Figure 4. Mean discharge rate \pm SEM of mesopontine cells $(n=49)$ as a function of state. $Q W$, Quiet waking; $A W$, active waking; $C A T$, cataplexy; REM, REM sleep; $N R E M$, non-REM sleep.

Of particular relevance to the present work is our finding that stimulation of the colocalized atonia and locomotor control mechanisms leads first to atonia and then to locomotor activity with a time lag ranging between 10 and $40 \mathrm{sec}$ (Lai and Siegel, 1991). This is the same sequence seen in REM sleep, where muscle tone suppression precedes the activation of mesopontine

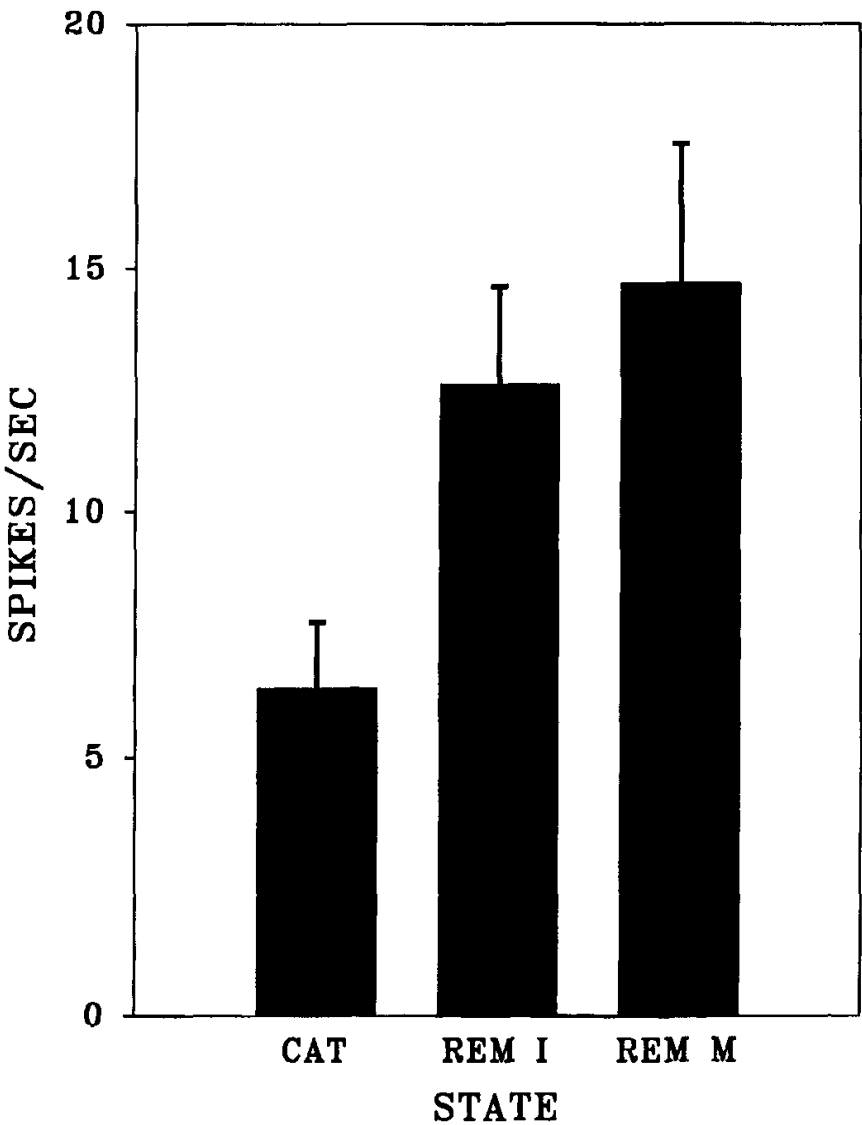

Figure 6. Discharge rates of mesopontine cells in cataplexy $(C A T)$ and in the initial period of REM sleep (REM I). Mean duration of cataplexy and initial period of REM sleep was 30 sec; mean duration of total REM sleep period for calculation of mean REM sleep rate (REM $M$ ) was $5.7 \mathrm{~min}(n=35)$.

units and correlated rapid eye movements. We hypothesize that in short-duration cataplexies, the atonia mechanism is activated, as at REM sleep onset, but the recruitment of the NMDAmediated phasic motor activation system is delayed. In extend-

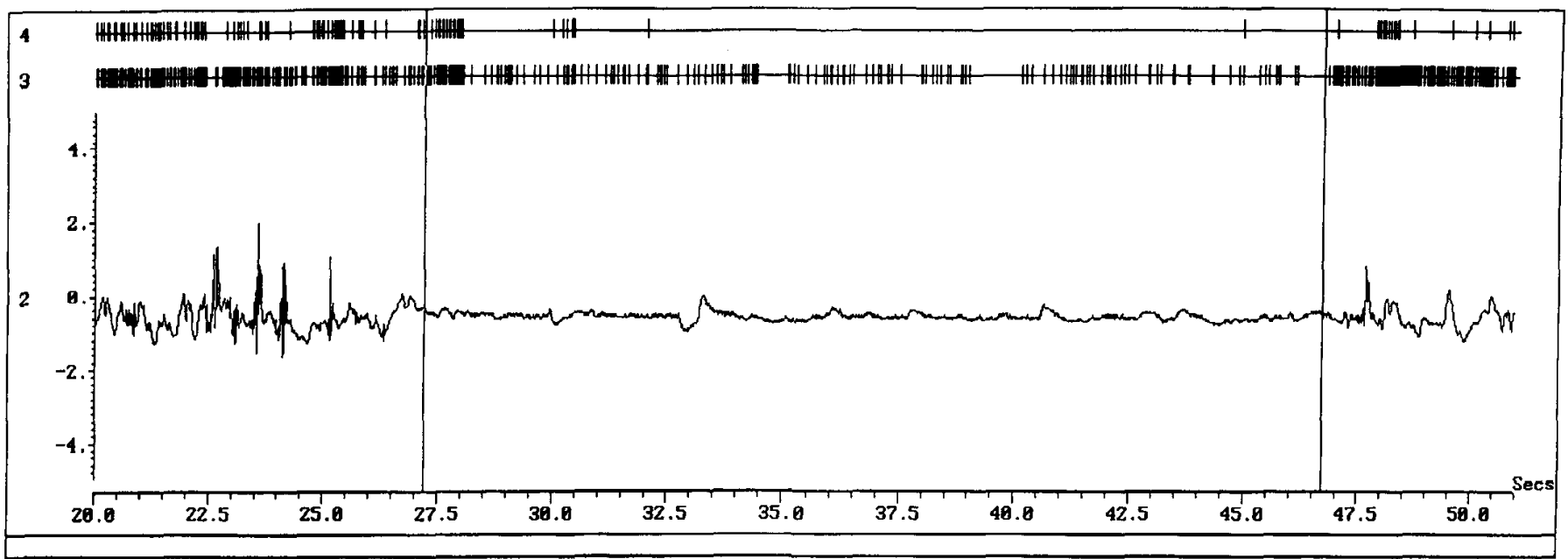

Figure 5. Computer display of two pontine units recorded simultaneously during cataplexy period. Vertical lines indicate onset and offset of cataplexy. Periods before and after cataplexy are waking. Top two channels display unit pulses; third channel displays EOG. Note the reduction of discharge in both units during cataplexy, and the concomitant reduction in eye movements. 


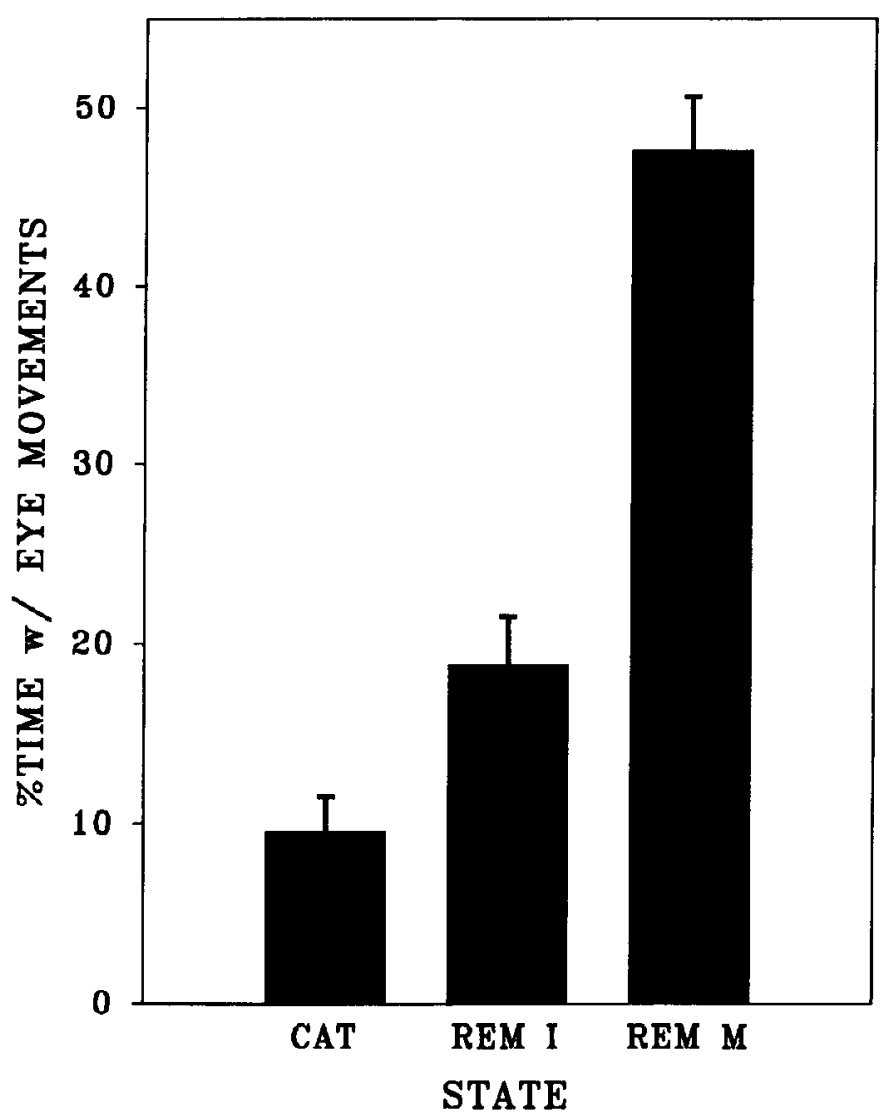

Figure 7. Eye movement as percentage of recording time for same intervals for which unit rates are displayed in Figure 6.

ed cataplexy periods, a gradual transition to REM sleep may occur (Guilleminault, 1976), including not only rapid eye movements, but also the loss of consciousness of the outside world that characterizes sleep. Thus, the activation of the REM sleep phasic motor mechanism during the atonic state either is causally related to the loss of consciousness or, perhaps more likely, is correlated with the spread of excitation to other brainstem systems whose activity is linked to loss of consciousness.

Because of the absence of cataplexy-on cells in the medial pons, we hypothesize that a neuronal subpopulation in the PPN/ LDT and lateral RPO atonia/locomotor control regions may be responsible for atonia in both REM sleep and cataplexy. According to this hypothesis, a cell population with activity selective for REM sleep and cataplexy should exist in these areas.

Our recent studies in the medial medulla support the idea that the atonia of cataplexy and REM sleep is mediated by a specialized subpopulation of cells. Most medial medullary cells, like the mesopontine cells recorded in the present study, were inactive in cataplexy but active in REM sleep (Siegel et al., 1991). However, we also found a group of medial medullary cells that were selectively active in cataplexy and REM sleep. These cells were localized to the ventral portions of nucleus magnocellularis, a region implicated in the suppression of tone in REM sleep (Sakai, 1980; Lai and Siegel, 1988; Schenkel and Siegel, 1989). These cells may be driven from a similar population of cataplexy-REM sleep-on pontine cells that have not yet been observed. One might predict the existence of such cells in the dorsolateral pons because REM sleep-on cells with projections to the medial medulla have been found in this region
(Sakai, 1980; Shiromani et al., 1987). However, it is also possible that the medullary "cataplexy-on" cells do not require mesopontine excitation to produce the pathological loss of muscle tone in cataplexy, perhaps being activated autochthonously or with facilitation from adjacent medullary autonomic regions (Siegel et al., 1989). Thus, the determination of the activity pattern of pontine "REM sleep-on" cells in cataplexy is critical to an identification of the circuit producing this state.

Further examination of the differences and similarities between cataplexy and REM sleep will not only shed light on the mechanism responsible for narcolepsy, but will also provide important information on the mechanisms responsible for the suppression of muscle tone in REM sleep and the control of muscle tone in relation to locomotion in waking states.

\section{References}

Aldrich MS, Frey K, Albin RL, Penney JB (1990) Muscarinic receptor autoradiographic studies of postmortem human narcoleptic brain. Sleep Res 19:179.

Baghdoyan HA, Rodrigo-Angulo ML, McCarley RW, Hobson JA (1987) A neuroanatomical gradient in the pontine tegmentum for the cholinoceptive induction of desynchronized sleep signs. Brain Res 414:245-261.

Baker TL, Dement WC (1985) Canine narcolepsy-cataplexy syndrome: evidence for an inherited monoaminergic-cholinergic imbalance. In: Rrain meshanisms of sleep (McGinty DJ, Drucker-Colin R, Morrison A, Parmeggiani PL, eds), pp 199-234. New York: Raven.

Boehme RE, Baker TL, Mefford IN, Barchas JD, Dement WC, Ciaranello RD (1984) Narcolepsy: cholinergic receptor changes in an animal model. Life Sci 34:1825-1828.

Chase MH, Morales FR (1989) The control of motoneurons during sleep. In: Principles and practices of sleep medicine (Kryger $\mathrm{MH}$, Roth T, Dement WC, eds), pp 74-85. Philadelphia: Saunders.

Duckwiler GR, Levesque M, Wilson CL, Behnke E, Babb TL, Lufkin $R$ (1990) Technical note: imaging of MR-compatible intracerebral depth electrodes. AJNR 11:353-354.

George R, Haslett WL, Jenden DJ (1964) A cholinergic mechanism in the brainstem reticular formation: induction of paradoxical sleep. Int J Neuropharmacol 3:541-552.

Guilleminault C (1976) Cataplexy. In: Narcolepsy (Guilleminault C, Dement WC, Passouant P, eds), pp 125-143. New York: Spectrum.

Henley K, Morrison AR (1974) A re-evaluation of the effects of lesions of the pontine tegmentum and locus coeruleus on phenomena of paradoxical sleep in the cat. Acta Neurobiol Exp (Warsz) 34:215232.

Honda Y, Doi Y, Juji T, Satake M (1984) Narcolepsy and HLA: positive DR2 as a prerequisite for the development of narcolepsy. Folia Psychiatr Neurol Jpn 38:360.

Jouvet M, Delorme F (1965) Locus coeruleus et sommeil paradoxal CR Soc Biol 159:895-899.

Kilduff TS, Bowersox SS, Kaitin KI, Baker TL, Ciaranello RD, Dement WC (1986) Muscarinic cholinergic receptors and the canine model of narcolepsy. Sleep 9:102-106.

Lai YY, Siegel JM (1988) Medullary regions mediating atonia. J Neurosci 8:4790-4796.

Lai YY, Siegel JM (1990) Muscle tone suppression and stepping produced by stimulation of midbrain and rostral pontine reticular formation. J Neurosci 10:2727-2738.

Lai YY, Siegel IM (1991) Pontomedullary glutamate receptors mediating locomotion and muscle tone suppression. J Neurosci 1 1:29312937.

Lai YY, Siegel JM (1992) Corticotropin-releasing factor mediated muscle atonia in pons and medulla. Brain Res, in press.

Lim RKS, Liu C, Moffitt RL (1960) A stereotaxic atlas of the dog's brain. Springfield, II: Thomas.

Lufkin R, Teresi L, Hanafee W (1987) New needle for MR-guided aspiration cytology of the head and neck. AJR 149:380-382.

Mignot E, Guilleminault C, Bowersox S, Frusthofer B, Nishino S, Maddaluno J, Ciaranello R, Dement WC (1989) Central alpha-1 adrenoceptor subtypes in narcolepsy-cataplexy: a disorder of REM sleep. Brain Res 440:186-191.

Mitler MM, Dement WC (1974) Cataplectic-like behavior in cats after 
micro-injection of carbachol in the pontine reticular formation. Brain Res 68:335-343.

Mitler MM, Nelson S, Hajdukovic R (1987) Narcolepsy: diagnosis, treatment, and management. Psych Clin N Am 10:593-606.

Ni HF, Zhang JX, Harper RM (1990) Respiratory-related discharge of periaqueductal gray neurons during sleep-waking states. Brain Res 511:319-325.

Rechtschaffen A, Wolpert EA, Dement WC, Mitchel SA, Fisher C (1963) Nocturnal sleep of narcoleptics. Electroencephalogr Clin Neurophysiol 15:599-609.

Rose D (1978) Midbrain and pontine unit responses to lordosis-controlling forms of somatosensory stimuli in the female golden hamster. Exp Neurol 60:499-508.

Sakai K (1980) Some anatomical and physiological properties of ponto-mesencephalic tegmental neurons with special reference to the PGO waves and postural atonia during paradoxical sleep in the cat. In: The reticular formation revisited (Hobson JA, Brazier MA, eds), pp 427447. New York: Raven.

Schenkel E, Siegel JM (1989) REM sleep without atonia after lesions of the medial medulla. Neurosci Lett 98:159-165.

Shiromani PJ, Armstrong DM, Bruce G, Hersh LB, Groves PJ, Gillin C (1987) Relation of pontine choline acetyltransferase immunoreactive neurons with cells which increase discharge during REM sleep. Brain Res Bull 18:447-455.
Siegel JM (1979) Behavioral functions of the reticular formation. Brain Res Rev 1:69-105.

Siegel JM (1989) Brainstem mechanisms generating REM sleep. In: Principles and practice of sleep medicine (Kryger MK, Roth WC, Dement WC, eds), pp 104-120. New York: Saunders.

Siegel JM, Tomaszewski KS (1983) Behavioral organization of reticular formation: studies in the unrestrained cat. I. Cells related to axial, limb, eye, and other movements. J Neurophysiol 50:696-716.

Sicgel JM, Tomaszewski KS, Wheeler RL (1983) Behavioral organization of reticular formation: studies in the unrestrained cat. II. Cells related to facial movements. J Neurophysiol 50:717-723.

Siegel JM, Tomaszewski KS, Fahringer H, Cave G, Kilduff T, Dement C (1989) Heart rate and blood pressure changes during sleep-waking cycles and cataplexy in the narcoleptic dog. Am J Physiol 256:H111H119.

Siegel JM, Nienhuis R, Fahringer H, Paul R, Shiromani P, Dement WC, Mignot E, Chiu C (1991) Neuronal activity in narcolepsy: identification of cataplexy related cells in the medial medulla. Science 262:1315-1318.

Van Dongen PAM, Broekkamp CLE, Cools AR (1978) Atonia after carbachol microinjections near the locus coeruleus in cats. Pharmacol Biochem Behav 8:527-532. 